\title{
LETTERS
}

Send your letters to the editor, British Dental Journal, 64 Wimpole Street, London W1G 8YS or by email to bdj@bda.org

Priority will be given to letters less than 500 words long. Letters should be typed. Authors must sign the letter, which may be edited for reasons of space

\section{Referral letters}

Sir, I read with interest the article by Djemal, Chia and Ubaya-Narayange (BDJ 2004, 197: 85) on the quality

improvements of referrals to a restorative department following the use of a referral proforma.

I recently undertook an audit as part of my SHO post at the Countess of Chester Hospital comparing the quality of referral letters from general dental practitioners and general medical practitioners to an oral and maxillofacial unit.

The aims of the audit were to assess and compare the quality of referral letters and to determine if a referral proforma would be of benefit to the unit following distribution to referring practitioners in the area.

A similar list of the minimum data required in a referral letter was compiled following a literature review and discussion with colleagues within the department. 50 GDP and 50 GMP letters were examined against the criteria and the results recorded.

Shortfalls in information were noted in a number of areas. The most significant finding was that only one third of GDP letters and two thirds of GMP letters contained information pertaining to the patients medical history; be it positive or negative findings.

It should be emphasised that within the hospital setting, details of the patient's medical history are crucial for the efficient, correct prioritisation and designation of patients to the appropriate clinic or waiting list particularly in an oral and maxillofacial unit. It is also an opportunity to double check medical details as patients may not always disclose the same information to the "unknown specialist.'

Interestingly, a paper published by Chambers and Scully entitled Medical information from referral letters ${ }^{1}$ reported a similar distribution of medical history inclusion in referral letters from GDPs and GMPs. This small study has highlighted that an unacceptable proportion of new referrals indicted the medical status of the

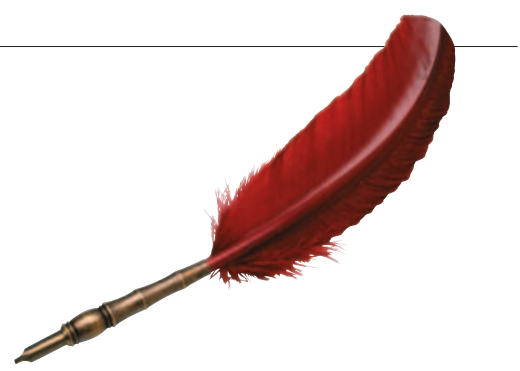

patient. It therefore raises a number of questions: are GDPs/GMPs exploring this aspect of the patient's history or are they simply omitting it from their referral letter?

Should the writing of referral letters be a formal inclusion in the undergraduate curriculum? Should more emphasis be placed on this aspect of care at postgraduate courses? Is it now time for clear recommendations (with respect to different specialities) to be published?

\section{R. Seed}

Liverpool

doi: 10.1038/sj.bdj.4811772

1. Oral Surg Oral Med Oral Pathol 1987; 64: 674-6.

\section{Medicines for vegetarians}

Sir, D. Sadoh (BDJ 2004, 197: 61) asked if there are any resources that address the provision of medicines to patients who are vegetarian or who have their diet restricted by cultural belief. He may find the booklet Drugs of porcine origin and clinical alternatives a useful resource.

Produced by the Medicines Partnership in March 2004, the booklet was put together in collaboration with the Muslim Council of Great Britain, a rabbinical authority and adviser to the Board of Deputies of British Jews, Clinical Leaders of Thrombosis UK and the Transcultural Nursing Association.

It includes practical advice and lists a number of resources for further information. It can be downloaded as a PDF file from the Medicines Partnership website at www.medicinespartnership.org, and is listed under 'Our Publications'. Paper copies can also be obtained free of charge from the Medicines Partnership by calling 0207572 2474.

Apart from medicines derived directly from animal sources e.g. porcine insulin and heparins, many medicines contain excipients that are animal derived. They include gelatin, used for most capsule shells and stearic acid/stearates e.g. magnesium stearate which are used in the production of some tablets. There is a 


\section{LETTERS}

move within the pharmaceutical industry to using animal-free alternatives to gelatin and stearates. Lactose, used in many tablets, is derived from milk (usually bovine) and is acceptable to vegetarians, but not to vegans. Other products that contain animal derivatives include saliva orthana, which contains porcine mucin and glucosamine (an alternative medicine preparation used for arthritis). Many preparations are derived from the crushed exoskeletons of shellfish, while other products are synthetic. Chondroitin (an alternative medicine preparation used for arthritis) is made from shark or bovine cartilage. For all licensed medicines, the manufacturer's Summary of Product Characteristics (SmPC) lists the pharmaceutical excipients included in the product. For the majority of marketed medicines the SmPCs can be found on the Electronic Medicines Compendium (eMC) at http://emc.medicines.org.uk.

Information on the animal content of medicines can also be obtained directly from the manufacturer, telephone numbers are listed in the back of the Dental Practitioners Formulary/British National Formulary (DPF/BNF).

Alternatively, local medicines information units can be contacted (see the inside cover of the DPF/BNF).

\section{Randall}

London

Sir, your correspondent wondered about which drugs are compatible with strict vegetarians or the various religious beliefs in our multi-cultural society. The source of the many ingredients used in the manufacture of medications is of great concern to orthodox Jews who only use animal products if the animals are acceptable to Jews and if they have been slaughtered according to Jewish law.

The manufacturing processes are investigated at great depth and continually updated. The information obtained is not only useful to orthodox Jews but to Muslims, (particular about Halal meat) vegetarians and others. This information is available in 'The Jewish Food Guide' available from www.kosher.org.uk.

\section{A. M. Bookey \\ London \\ doi: 10.1038/sj.bdj.4811773 \\ NICE guidelines}

Sir, NICE guidelines for impacted third molar removal were published in March $2000^{1}$.

Their aim was to discontinue prophylactic removal of pathology-free impacted lower third molars on the NHS. Pathologies that were deemed to indicate surgical removal were; unrestorable caries, severe or recurrent pericoronitis, pulpal or periapical pathology, cellulites, abscesses and osteomyelitis, resorption, fracture, follicular pathology, tumour resection and impedance of surgical field.

It is important to comply with these guidelines to avoid unnecessary complications from surgery, namely lingual and ID nerve paraesthesia, to avoid unnecessary general anaesthetics and it is a waste of NHS resources removing caries free teeth. Our department, the Maxillofacial Unit of Derbyshire Royal Infirmary, recently carried out an audit of the last 50 patients who were referred by their GDP for surgical removal of their lower third molars.

The aim of the audit was to see if GDPs were compliant with NICE guidelines when referring patients. The results showed that $38 \%$ of patients were referred back to their dentist without undergoing any treatment i.e. the teeth were noncompliant with NICE guidelines.

This could be seen as a waste of approximately 4.75 hours of clinical time over this period of 3 months. Attending an unnecessary hospital appointment also inconvenienced these patients.

By preventing some of these unnecessary referrals we would potentially decrease waiting list time for other patients, including those with more serious complaints and those who meet NICE criteria.

Our results suggest that some of the referrers in our catchment area would benefit from re-inforcement of the NICE guidelines to cut down on unnecessary referrals.

N. J. Milner

N. A. Smithson

Nottingham

doi: $10.1038 /$ sj.bdj.4811774

1. National Institute for Clinical Excellence. Guidance on the removal of wisdom teeth. May 2000.

\section{Financial concessions}

Sir, in response to the letter in your columns by Anthony Townsend, representing the policy of the GDC regarding the ARF, I feel it necessary to make the following comments.

In nearly all walks of life it is considered that retired pensioners over the age of 65 do deserve certain financial concessions, bearing in mind that whatever the level of pension income, it is fairly fixed in any particular year, and, unlike full or part-time working GDPs, cannot be increased except by going back into dental practice.

The concessions given are many, welcome, and well deserved by a hard working dentist, who has, as in my own case, put in over 44 years at the "coalface'. It is now considered to be accepted that one can expect free prescriptions, bus passes, reduced entry to almost any public building/exhibition and reduced subscriptions to clubs and organisations, including the BDA (£82pa instead of £380pa). I have even found that when skiing in both Europe and North America, discounts as high as 40\% are available to the over 65 's for what are normally very expensive ski-lift passes!

It might come as a big surprise to our dental profession that GMPs etc who have reached 65 and over and keep up to date can keep their registration going for free! In view of the huge shortage of dentists in the UK and the great lengths that the authorities are going to in order to attract the retired and other categories of non-practising dentists back to work, why on earth has the GDC imposed this draconian ARF?

I for one, will not be renewing my registration and will effectively have my name erased from the register. What testimony to 44 years of service to the community!

\section{G. Dexter}

Crawley

Sir, I was a qualified dentist practising for 42 years after qualifying at the $\mathrm{RDH}$, which incidentally was closed because of a glut of dentists.

I now find that I too am no longer on the register because I did not pay the nearly $£ 400$ requested. This is after my 60 years being on it - in part as an RAF dentist and then in private practice working as described by Dr Webster, (BDJ 2004, 197: 63) for a mere financial pittance under the NHS.

I find it cruel and heartless that this came about. It is absolutely unnecessary because in no way could we practise any more because of age and necessary annual attendance at courses.

It is absolutely cruel and all who read this should realise that this could happen to them and persuade the powers that be - the GDC - to change their mind and allow the older dentists to remain on the register after a lifetime of dentistry. When I remonstrated in a letter to them, no reply was received.

\section{S. Taylor \\ Kingston}

doi: $10.1038 /$ sj.bdj.4811775 